\title{
Current Trends in Support of E-government by Modern Smart Technologies
}

\author{
Dusan SOLTES \\ Faculty of Management, Comenius University, \\ Odbojarov 10, Bratislava, 820 05, Slovakia \\ Dusan.soltes@fm.uniba.sk
}

\begin{abstract}
Since its inception by the Lisbon strategy 2000 on eEurope strategy and then its continuation through i2010 strategy up to now with the Horizon 2020 in support of the Innovative Europe 2020, the applications of smart ICT in the EU has passed a rather complex and sometimes also a quite controversial development process .
\end{abstract}

In the following parts of this paper we are dealing with the current status as achieved in the development of the future EU as the e-Europe as well as we are trying to find the ways and means how to accelerate the entire development in this respect within the selected ten sectors of the future e-Europe..

Keywords-e-Europe; e-Government; G2G; G2C; G2B

\section{INTRODUCTION}

In spite of the above existing problems and weaknesses in the development of the e-Europe there has been gradually going an increase in funding for the R\&D activities including research for the ICT and/or IST and related smart technologies programs from around 35 billion Euro for 6FP (2002-6) to 52 billion Euro for 7FP (2007-13). And now under the HORIZON 2020 it goes up to 70 billion Euro for years 2014-20. What by itself is a steadily growth in financial support to the EU R\&D but it remains still only fraction of the funding going to the most controversial CAP - Common Agricultural Policy that gets about the same amounts or in other words almost the half of the EU annual budget but ... not for 5-7 years as it is in case of the support to R\&D but for annual subsidies to the EU farmers.

However, in spite of these objective but also not so objective problems there has been achieved some evident progress regarding applications of smart ICT technologies for the needs of the future electronic Europe although there are still some gaps between the achievements of the "old" EU15 and the "new" EU12 and now also EU13. According to some key sectors the main results but also some problems as so far achieved and/or identified in the e-Europe development are as they are presented in the following parts of this paper. :

\section{SELECTED APPLICATION AREAS OF THE FUTURE E- GOVERNMENT AS A PART OF THE EU E-EUROPE STRATEGY}

In this part of the paper we are going to deal at least very briefly with some key application areas of the future e-Europe. Into these areas we have selected the following ten key application areas as follows:

\section{- e-Government}

$\begin{array}{ll}\text { - } & \text { e-Signature } \\ \text { - } & \text { e-Invoicing and e-Procurement } \\ \text { - } & \text { e-Health } \\ \text { - } & \text { e-Surveillance } \\ \text { - } & \text { e-Inclusion } \\ \text { - } & \text { e-Education } \\ \text { - } & \text { e-Content and e-Libraries } \\ \text { - } & \text { e-Knowledge and e-skills } \\ \text { - } & \text { e-Infrastructure }\end{array}$

\section{A. E-Government}

As far as the development of the future e-Government as one of the key application areas of the future e-Europe is concerned, the main results and challenges in this problem area have been within the following main three government services and that being G2C, G2B, G2G. The G2C stands for the governmental services of the future eGovernment to citizens. The G2B means the services of the future e-Government to and/or for businesses. and the G2G represents the governmental agendas and interactions between and among the various governmental agencies on the central as well as regional levels. In general we could state in this connection that even after the more than 14 years since the inception of the Lisbon strategy the main problems have been basically still the same ones i.e. that some fundamental technical preconditions have not yet been created like e.g. the e-Signature as the main access tool for becoming an authorized user for various eGovernment applications. As far as the Government services to citizens under the G2C are concerned we could state that only now some main preconditions are created e.g. in many especially new EU member states including our country of Slovakia. The same we could say also regarding the G2B as to open e.g. a new business even on the level of SME nowadays requires again various applications, permissions and authorizations from various governmental agencies.

\section{B. E-Signature.}

This very important e-tool for carrying out any and/or all fundamental e-activities has not been still generally available across the e-EU in the form that would meet the general requirements of the EU common market i.e. that it will be easily and equally available and functional across the entire single market of the Union. In different countries there was applied a different approach, so in principle there exist 28 different versions of e-signature. Some of them are offering it for free, in some other 
countries like e.g. in Slovakia it has been available only for a rather high fee of around 80 Euro. But there are still not yet so many applications as we have mentioned it above where to use it. Hence, especially in the case of SME, citizens, etc. it is rather too expensive if there are not available so many e-applications where e.g. citizens or SME could use it.

\section{E-Invoicing and e-Procurement.}

E-Invoicing and e-Procurement are other main and very important preconditions for developing modern e-Business within the future EU digital internal e-market. There again has been achieved some progress on the national level of individual EU member states but just a very little regarding the unified "EU common e-digital market" of the EU28. The situation is similar like in the case of e-signature i.e. there are more or less working national systems but not the one for the needs of the EU future common digital emarket. One of the main problems is not only the technological one but also the language one as most countries are publishing their e-tenders only in the national languages and thus cutting off potential suppliers from other EU member states.

\section{E-Health.}

Without any doubts the e-health is one of the key sectors of the future e-Europe if we take into account the demographic development in the EU and especially very fast growing the share of the aging population on its overall population. Again as in other areas also in this one, some progress has been achieved on the national level especially in some most developed EU member states and especially in its Nordic group of states but there is again existing a big problem regarding the e-Health for the entire e-Europe. The main problems again are not in the technological aspects of its implementation but in the legislative and organizational ones. There has been existing already for years a kind of the "common" EU Health Insurance Card but in its classical plastic form only. It means that if the patient needs some medical care outside of its national territory the main problem is that foreign doctor has no information about the particular patient as the above plastic card contains no e-medical records, diagnosis, medications, etc. Hence for the foreign doctor it is sometimes too risky to offer any kind of medical services without this key medical information.

\section{E. E-Surveillance.}

By a certain paradox of the entire e-Europe implementation strategy that although this specific sector of the future e-Europe originally has not been a part of it at all, in practice it is one of the most developed and according to many accounts one of the sectors being truly and fully developed across the entire EU. As in various other similar problem areas also in case of e-surveillance its enormous development and almost perfection has been achieved as a kind of secondary result of the ongoing technological development in the modern smart ICT and their applications as it is in case of e.g. mobile phones, tablets, social networks, navigation systems, etc. Hence even without any special interest and intentions of the operators and through them all interested parties either from the governmental as well as private sector they all have at their finger- tips enormous amounts of and very often even most sensitive personal, business, state/administrative information. As our ongoing research under the EU funded projects SMART, CONSENT, RESPECT have documented then it is only a question of legislative, ethical and administrative respects to what extent and if at all that very rich source of data would be used properly exclusively only for the purposes that data was officially recorded for, or it would be misused also for some other often discriminatory, non-ethical or even criminal purposes.

\section{F. E-Inclusion}

Thank to above technological progress being achieved especially in popularity of mobile phones but also tablets, smart phones, etc. as we have been dealing with them in the previous part of this paper also one of the critical and most important parts of all strategies on the e-Europe has become a very practical and relatively easy to be implemented. Although again as in various other similar cases the strategies since the first one i.e. regarding the EU/Lisbon strategy have not been quite clear how to achieve the full e-Inclusion i.e. that every citizen of the future e-Europe will become integral part of this modern information society where everybody will become eincluded one. Thanks again especially to popularity of mobile phones and/or in particular of their smart phone versions it has become a common reality. From smallest kids up to the oldest senior citizens all of them are nowadays users of this mobile latest smart ICT and thus also an integral part of their e-inclusion into the contemporary modern information society of the EU.

\section{G. E-Education.}

As mentioned in the previous part of this paper, the potential of the development in e-education especially regarding the so-called long-life education especially for adults as well as senior citizens has acquired through above mobile ICT quite new potential horizons. So far this potential has not yet been fully utilized especially in case of elderly and senior citizens for whom the e-education and/or better m-education is the most convenient ways together with the TV how to keep them up-to-date regarding the abruptly changing world. Hence in this respect there are quite big reserves and also potential to use the latest ICT for long life and/or various other forms of informal education.

\section{H. E-Content and e-Libraries}

Very closely related issue to the above problems regarding the e-education has been the problem of econtent and e-libraries. As we have mentioned also above there is still existing to some extent the lack of programs that would be supporting e-learning, life long and/or other forms of informal education i.e. educational forms especially intended for people who are already not a part of the regular formal educational systems at schools, etc. In this specific respect the role of the rich e-content and elibraries are representing a very important and needed part of the e-Europe strategy. It is clear that some progress has already been achieved also in this respect but the more consistent progress has been to some extent negatively effected by the lack of funding for the necessary staffing as needed for this kind of work. In most cases the practice in this problem area has been based on utilization of the work 
of some volunteers who in cooperation with librarians have been providing scanning of documents, materials, etc. of the future e-content and e-libraries.

\section{I. e-Knowledge and e-Skills.}

It is absolutely necessary that the tasks of e-Europe strategy in the above areas of e-Content and e-Libraries have to support first of all, all various forms of e-content that represents the best what has been achieved in all various forms and categories of the social, economic, cultural, social, etc. areas of the human and societal activities. After all it was one of the key strategic objectives of the original Lisbon strategy that has as one of its main objectives defined the future EU as the most advanced knowledge based economy and information society in the world, The main problem has been that until now there has not been found a system that would guaranty that the EU remarkable R\&D results would be fully utilized and implemented also in the practice on the EU as well as national level of individual member states.

\section{J. e-Infrastructure..}

It is absolutely clear that all the above mentioned problem areas of the future e-Europe and of course also many other of them not to mentioned here in order to be developed properly are fully depended on the existence and some availability of suitable modern latest ICT technological basis. Or as it has been characterized in all EU development strategies it has to be based on the modern technological "backbone" based on the cheap and widely available Internet and the same also regarding the mobile phone networks with again cheap roaming across the entire EU, etc. In this respect all EU strategies on the development of the future modern e-Europe have stressed first of all also the necessity to build a EU wide high speed broadband Internet that would cover all EU member states in full of its availability by the target year 2020 under the HORIZON 2020.strategy at the latest.

\section{SOME MAIN CONCLUSIONS AND RECOMMENDATIONS}

In conclusion we would like just to state that as we have presented it in the previous parts of this paper it is clear that since the inception of the original Lisbon strategy on e-Europe some evident progress has been achieved in implementation of all various areas of this strategy. In many cases as we have tried also to point it out it is not needed much more effort to achieve the objectives in full. But in any case it would require a better coordinated approach especially from the EU member states regarding e.g. their willingness to use the results of the EU funded R\&D projects rather than to emphasize their own "ambitions" to build the future e-Europe more through various national initiatives than to accept and fully utilize results of the EU funded projects.

\section{SUMMARY}

In summary it could be stated that the utilization of the latest smart ICT has been becoming the key aspect of the contemporary development and implementation of the eGovernment in all EU member states and especially it is becoming the most crucial success factor in the EU NMS new member states due to their some still existing delay behind the so called "old" EU members. In this respect most will depend upon the way how the EU NMS will manage to comply with the main strategic objectives of the current ongoing implementation of the EU strategy HORIZON 2020 and/or EUROPE 2020.

\section{ACKNOWLEDGMENT}

At this part of our paper we would like to acknowledge the funding we have received for our EU projects SMART, RESPECT and CONSENT under the previous 7th FP of the European Union. Our many thanks and acknowledgment goes also to Prof. J. Cannataci of the University of Gronningen for his leadership and overall support to our research under the above three EU funded projects.

\section{REFERENCES}

[1] J. Cannataci et al: EU/FP7-SSH-2009-A CONSENT Collaborative project (small or medium scale focused project on Consumer sentiments regarding privacy on user generated kontent (UGC) services in digital economy, Annex I - Description of Work, University of Central Lanceashire, Preston, UK September 2009

[2] Cannataci, J. et al: EU/FP7/SSH-2009-A CONSENT Project, WP3 - Mapping Privacy Settings, D 3.1. Survey Report, University of Malta, La Valetta, October 2010

[3] D. Soltes at al: EU/FP7/SMART Project, Work Packages WP2-8 with thé results as achieved in thé Slovak Republic gradually in years 2011-13, FM UK Bratislava, March 2013 